\title{
Effects of exercise training on stress-induced vascular reactivity alterations: role of nitric oxide and prostanoids
}

\author{
Thiago Bruder-Nascimento ${ }^{1}$, Samuel T. Silva ${ }^{2}$, \\ Patrícia A. Boer ${ }^{3}$, Sandra Cordellini ${ }^{1}$
}

\begin{abstract}
Background: Physical exercise may modify biologic stress responses. Objective: To investigate the impact of exercise training on vascular alterations induced by acute stress, focusing on nitric oxide and cyclooxygenase pathways. Method: Wistar rats were separated into: sedentary, trained (60-min swimming, 5 days/week during 8 weeks, carrying a 5\% body-weight load), stressed ( 2 h-immobilization), and trained/stressed. Response curves for noradrenaline, in the absence and presence of L-NAME or indomethacin, were obtained in intact and denuded aortas $(n=7-10)$. Results: None of the procedures altered the denuded aorta reactivity. Intact aortas from stressed, trained, and trained/stressed rats showed similar reduction in noradrenaline maximal responses (sedentary $3.54 \pm 0.15$, stressed $2.80 \pm 0.10^{*}$, trained $2.82 \pm 0.11^{*}$, trained/stressed $2.97 \pm 0.21 *, * \mathrm{P}<0.05$ relate to sedentary). Endothelium removal and L-NAME abolished this hyporeactivity in all experimental groups, except in trained/stressed rats that showed a partial aorta reactivity recovery in L-NAME presence (L-NAME: sedentary 5.23 $\pm 0,26^{\#}$, stressed $5.55 \pm 0.38^{\#}$, trained 5.28 $\pm 0.30^{\#}$, trained/stressed 4.42 $\pm 0.41,{ }^{\#} \mathrm{P}<0.05$ related to trained/stressed). Indomethacin determined a decrease in sensitivity (EC50) in intact aortas of trained rats without abolishing the aortal hyporeactivity in trained, stressed, and trained/stressed rats. Conclusions: Exercise-induced vascular adaptive response involved an increase in endothelial vasodilator prostaglandins and nitric oxide. Stress-induced vascular adaptive response involved an increase in endothelial nitric oxide. Beside the involvement of the endothelial nitric oxide pathway, the vascular response of trained/stressed rats involved an additional mechanism yet to be elucidated. These findings advance on the understanding of the vascular processes after exercise and stress alone and in combination.
\end{abstract}

Keywords: vasodilator prostanoids; nitric oxide; exercise training; acute stress; aorta reactivity; physical therapy.

\section{HOW TO CITE THIS ARTICLE}

Bruder-Nascimento T, Silva ST, Boer PA, Cordellini S. Effects of exercise training on stress-induced vascular reactivity alterations: role of nitric oxide and prostanoids. Braz J Phys Ther. 2015 May-June; 19(3):177-185. http://dx.doi.org/10.1590/bjpt-rbf.2014.0088

\section{Introduction}

Influences of stress on organic responses are largely known. Although virtually all organs are affected by stress-exposure, the neuroendocrine, cardiovascular, immune, and gastrointestinal systems are main targets to functional changes. In this context, a decreased vascular reactivity to noradrenaline and an increased vascular reactivity to acetylcholine have been described after stress-exposure ${ }^{1}$. The literature also reports that stress-induced vascular alterations are dependent on endothelial integrity and nitric oxide release ${ }^{2}$.

However, regular physical activity has been associated with a reduced incidence of cardiovascular diseases. Exercise training in both hypertensive subjects and spontaneously hypertensive rats results in blood pressure decrease ${ }^{3}$. Chronic exercise also improves the vasodilatory mechanisms mediated by endothelium-dependent relaxing factors released in the cardiac and skeletal muscles, kidney, and vascular beds $^{4,5}$. Moreover, exercise increases endothelial nitric oxide system activity and enhances the contribution of prostanoids to endothelium-dependent relaxation in coronary arteries ${ }^{1,6}$.

There is also evidence suggesting that physical activity and exercise might modify biologic stress response ${ }^{7,8}$. In this context, studies have supported the benefits of physical activity and exercise on psychological health as well as cardiovascular response to acute stress $^{8-12}$. Aerobically trained individuals exhibit lower sympathetic nervous system (e.g. heart rate) reactivity and enhanced cardiovascular efficiency (e.g. lower

\footnotetext{
${ }^{1}$ Departamento de Farmacologia, Instituto de Biociências, Universidade Estadual Paulista (UNESP), Botucatu, SP, Brazil

${ }^{2}$ Departamento de Proteção Vegetal, Faculdade de Ciências Agronômicas, UNESP, Botucatu, SP, Brazil

${ }^{3}$ Faculdade de Ciências Médicas, Universidade Estadual de Campinas (UNICAMP), Campinas, SP, Brazil

Received: May. 09, 2014 Revised: Nov. 06, 2014 Accepted: Nov. 18, 2014
} 
vascular reactivity and decreased recovery time) in response to physical and/or psychological stress? Those who are physically fit are more resilient to the effects of stress, such as high work demands, resulting in less heart disease and associated mortality ${ }^{13}$.

Despite the reports on vascular reactivity changes related to exercise training and stress-exposure alone, the role of physical activity and exercise on stressinduced vascular alterations as well as the mechanisms involved in these conditions require further investigation. Thus, the aim was to evaluate the effects of exercise training and stress alone on vascular function as well as the impact of exercise training on the vascular adaptive response to acute emotional stress, focusing on nitric oxide and cyclooxygenase pathways. Exploring the role of exercise on the vascular adaptive response to stress may improve the treatment and prevention of stress-related cardiovascular diseases and, thus, has important implications for public health.

\section{Method}

\section{Animals}

Experiments were performed in male Wistar rats (6-16 weeks of age) provided by Universidade Estadual Paulista (UNESP), Botucatu, SP, Brazil. They were housed three per cage 1 week before the study was initiated and had free access to regular lab chow and water. Lights in the animal room were set on 12:12-h cycle with temperature maintained at $22 \pm 1^{\circ} \mathrm{C}$. Animal procedures were in accordance with the principles and guidelines of the National Council of Control of Animal Experimentation and the study was approved by the Animal Research Ethics Committee of Instituto de Biociências, UNESP (protocol number: 67/03-CEEA).

\section{Body and organ weights}

The animals were weighed weekly throughout the exercise training period. The cardiac hypertrophy was evaluated by left ventricle weight normalized for body weight (LV weight/BW) and employed to assess the efficacy of exercise training ${ }^{14}$. The weight of the adrenals was employed to assess the efficacy of stress induction ${ }^{15}$.

\section{Measurement of blood pressure}

Systolic blood pressure, in conscious rats, was measured weekly throughout the exercise training period, using tail-cuff plethysmography (Narco Bio-Systems, Houston, Texas, USA). The rats were pre-warmed for 10 to $15 \mathrm{~min}$ and placed into a restrainer for blood pressure measurement. Three consecutive recordings ( $\sim 1$ min apart) were performed, and the mean of these three measurements was recorded.

\section{Adaptation period}

To avoid a considerable loss of rats and to reduce the animals' stress, the rats from training groups were submitted to a gradual but brief adaptation period (Figure 1). During the first pre-training week, the 6-week old animals were placed in contact with increasing volumes of heated water and periods of exposure $\left(28 \pm 1^{\circ} \mathrm{C} ; 15-60 \mathrm{~min} /\right.$ day, 5 sessions $)$ within a tank $(35 \times 17 \times 50 \mathrm{~cm})$ in order to adapt to the water. Subsequently, the rats were submitted to a second pre-training week consisting of forced swimming sessions in water at $28 \pm 1{ }^{\circ} \mathrm{C}$, for $60 \mathrm{~min} /$ day, carrying a load strapped to their chests. The workload was gradually increased (1-5\% of body weight) until the rats could swim for 60 min wearing a chest load weighing $5 \%$ of body weight. Thereafter, the workload was constant.

\section{Exercise training program}

At the end of the adaptation period, the rats (8-week old) were submitted to the exercise training program (Figure 1). Additionally, 8-week old sedentary rats $(\mathrm{S})$ remained in their cages during the same time period (Figure 1).

Exercise training consisted of a forced swimming session once a day for a period of 8 weeks (five days/week). Rats were submitted individually to a forced swimming session in warmed water at $28 \pm 1{ }^{\circ} \mathrm{C}$ for $60 \mathrm{~min}$, carrying a load weighing $5 \%$ of
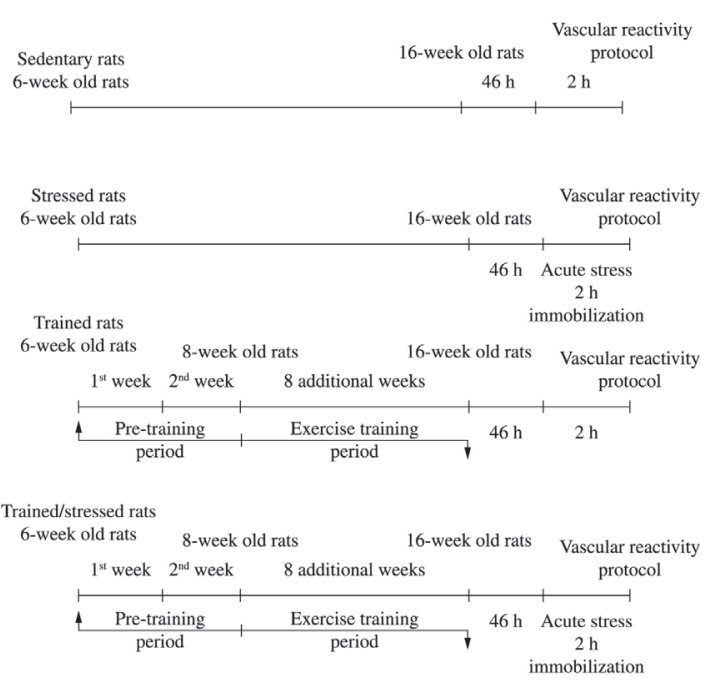

Figure 1. Experimental design. 
body weight strapped to their chests. The sessions were performed between 1:00 and 2:00 pm. During the exercise session, the sedentary rats were kept in their home cages. This swimming protocol has been characterized previously as being of low to moderate intensity and of long duration ${ }^{16}$. Forty-eight hours after the last exercise session, the trained 16-week old rats $(\mathrm{T})$ were killed by decapitation (Figure 1).

\section{Stress induction}

Forty-six hours after the last exercise session, a group of 16-week old trained rats was submitted to a single stress session (T/St) (Figure 1). Additionally, a group of 16-week old sedentary rats was submitted to a single stress session (St) (Figure 1).

The stressor agent consisted of immobilization for $2 \mathrm{~h}$ in a $5 \times 27 \mathrm{~cm}$ metal tube, individually adapted to provide a tight restriction of movements, but allowing the animal to breathe normally. This acute stress exposure took place between 10:00 am and 2:00 pm. During the stress session, the non-stressed rats were kept in the home cage. Immediately after stress exposure the rats were killed by decapitation (Figure 1).

\section{Immunohistochemical procedures}

Groups of sedentary and trained rats, exposed or not to stress were anesthetized with a mixture of ketamine (75 mg. $\mathrm{kg}^{-1}$ body weight, i.p.) and xylasine (10 mg. $\mathrm{kg}^{-1}$ body weight, i.p.) and the level of anesthesia was controlled by monitoring the corneal reflex. The animals were then perfused by the left carotid artery with saline containing heparin $(5 \%)$ for $15 \mathrm{~min}$ under constant pressure, followed by perfusion with $0.1 \mathrm{M}$ phosphate buffer ( $\mathrm{pH} 7.4)$ containing $4 \%(\mathrm{w} / \mathrm{v})$ paraformaldehyde for $25 \mathrm{~min}$. After perfusion, aortas were removed, weighed, and representative samples were fixed in $4 \%$ phosphate-buffered formalin during $24 \mathrm{~h}$ for paraffin embedding. For immunohistochemical analysis, we used anti-neuronal nitric oxide synthase ( $\mathrm{NOS}_{1}$ ) antibody. Protein expressions were immunohistochemically detected using the avidin-biotin-peroxidase method. Briefly, deparaffinized 5- $\mu$ m-thick aorta sections on poly-1-lysine coated slides were treated with $3 \% \mathrm{H}_{2} \mathrm{O}_{2}$ in phosphate-buffered saline for $15 \mathrm{~min}$, nonfat milk for 60 minutes, primary antibodies for $60 \mathrm{~min}$, and avidin-biotin-peroxidase solution (Vector Laboratories Inc, CA, USA, 1:1:50 dilution). Antigen retrieval was performed by boiling in
$0.01 \mathrm{M}$ citrate buffer ( $\mathrm{pH}$ 6.0) in a microwave oven $(1,300 \mathrm{~W})$ twice for 5 minutes each. The chromogen color was accomplished with 3,3'-diaminobenzidine tetrahydrochloride (DAB, Sigma-Aldrich Co., St. Louis MO, USA ) as the substrate to demonstrate the sites of peroxidase binding and slides were counterstained with Harris's hematoxylin.

\section{Vascular reactivity protocol}

Immediately after the rat was killed, the descending thoracic aorta was excised and trimmed free of adhering fat and connective tissue. Two transverse rings of the same artery, each about $4 \mathrm{~mm}$ in length, were cut and mounted at the optimal length for isometric tension recording in organ chambers. One ring served as control (intact aorta), while the endothelium was mechanically removed from the other (denuded aorta) by gently rubbing the luminal surface. Briefly, preparations were mounted in organ baths containing $7 \mathrm{ml}$ of Krebs-Henseleit solution, with composition in $\mathrm{mM}$ : $\mathrm{NaCl} 113.0 ; \mathrm{KCl} 4.7$; $\mathrm{CaCl}_{2} 2.5 ; \mathrm{KH}_{2} \mathrm{PO}_{4} 1.2 ; \mathrm{MgSO}_{4} 1.1 ; \mathrm{NaHCO}_{3} 25.0$; Glucose 11.0; ascorbic acid 0.11. The bathing fluid, kept at $36.0 \pm 0.5^{\circ} \mathrm{C}$, was saturated with a gas mixture of $95 \% \mathrm{O}_{2}, 5 \% \mathrm{CO}_{2}$. The preparations were allowed to equilibrate for at least $1 \mathrm{~h}$ under a resting tension of $1.5 \mathrm{~g}$, which is optimal for inducing maximum contraction. Tension was recorded with a physiograph (Ugo Basile, Italy).

Cumulative concentration-effect curves were constructed from the response of the tissue to noradrenaline in presence or absence of inhibitors $\mathrm{N}^{\mathrm{G}}$-nitro-L-arginine methyl ester (L-NAME, $3 \times 10^{-4} \mathrm{M}$ ) or indomethacin $\left(10^{-5} \mathrm{M}\right)$. At the end of the curves, single doses of acetylcholine $\left(10^{-6} \mathrm{M}\right)$ and sodium nitroprusside $\left(10^{-4} \mathrm{M}\right)$ were used to test the integrity of endothelial and smooth muscle layers, respectively. Endothelium and smooth muscle were considered to be intact if the acetylcholine and sodium nitroprusside-induced relaxation of the pre-contracted aorta was greater than $70 \%$ and $90 \%$ respectively.

\section{Drugs and solutions}

The following drugs were used: acetylcholine bromide, noradrenaline bitartrate, sodium nitroprusside, $\mathrm{N}^{\mathrm{G}}$-nitro-L-arginine methyl ester, indomethacin (all obtained from Sigma Chemical Co., St Louis, Missouri, USA). All drugs were dissolved in Krebs-Henseleit solution. 


\section{Statistical analysis}

The concentration of vasoactive agents producing a response that was $50 \%$ of the maximum (EC50) was calculated in each experiment. Data are presented using descriptive statistical procedures (mean, standard error of mean, confidence interval). Statistical analyses were performed using multifactorial ANOVA (SIGMASTAT 3.2). Exercise training and stress were the factors in the analysis and represent the independent variables. A $P$ value less than 0.05 was considered to be statistically significant. The Tukey multiple comparisons test was used to test differences among means. If necessary, dependent variables were log transformed prior to parametric testing.

\section{Results}

\section{Effects of exercise training associated or not with acute stress on body and organ weights and blood pressure}

The exercise training determined cardiac hypertrophy [left ventricle/body weight mean \pm SEM $(\mathrm{mg} / \mathrm{g})$ : $\mathrm{S} 1.71 \pm 0.71, \mathrm{n}=7$; T $2.17 \pm 0.55^{*}$, n=9; St $1.83 \pm 0.31$, $\mathrm{n}=9$; and $\mathrm{T} / \mathrm{St} 2.34 \pm 0.61^{\dagger}, \mathrm{n}=10 ; * \mathrm{P}<0.05$ related to sedentary group; ${ }^{\dagger} \mathrm{P}<0.05$ related to stressed group].
Stress-exposure induced a decrease in adrenal weight [mean \pm SEM (gx100): S 8.13 \pm 0.37 , T $8.38 \pm 0.45$, St $6.54 \pm 0.42 *$, T/St $6.59 \pm 0.10^{\dagger},{ }^{*} \mathrm{P}<0.05$ related to sedentary group, ${ }^{\dagger} \mathrm{P}<0.05$ related to trained group, number of animals per group $=7$ ].

The body weight and blood pressure was similar for sedentary and trained rats (Figure 2).

\section{NOS $_{1}$ expression}

The immunohistochemical results show that both exercise training and stress exposure increased the aortic $\mathrm{NOS}_{1}$ expression. Similarly, the association of these procedures determined an increase in the aortic $\mathrm{NOS}_{1}$ expression compared to the non-stressed sedentary group, however in a lower extension than observed in the aorta of rats submitted to exercise training and stress alone (Figure 2).

\section{Vascular reactivity}

Both stress exposure and exercise training similarly reduced the maximal responses to noradrenaline of the intact aortas compared to non-stressed sedentary rats, without affecting the EC50 values. The combination of both procedures did not potentiate
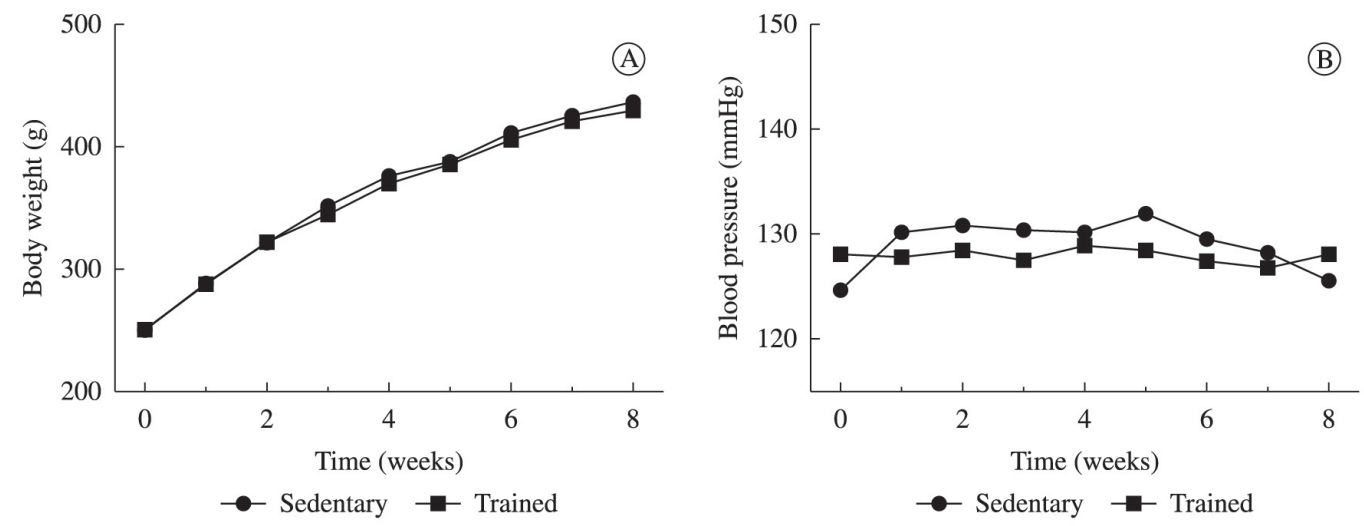

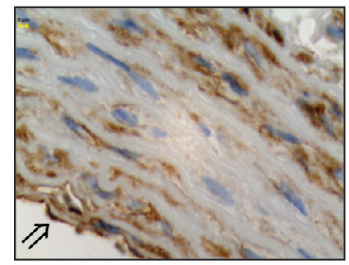

Sedentary

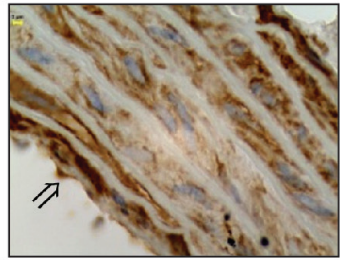

Trained

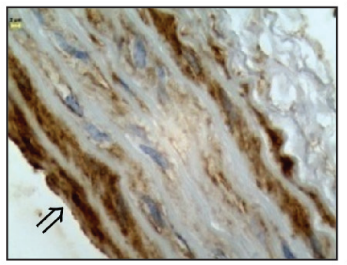

Stressed

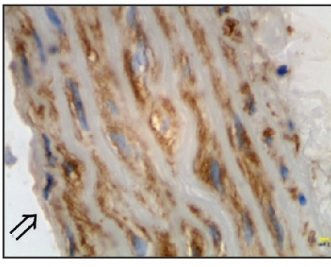

Trained/Stressed

Figure 2. Body weight (A), systolic blood pressure (B), and immunohistochemical evaluation of neuronal nitric oxide synthase expression (brown) and nucleus (blue) in thoracic aortas from 16-week old rats (C). The arrows indicate the endothelial layer. Groups: sedentary, trained (60-min swimming sessions, 5 days/week during 8 weeks, with a $5 \%$ body weight load attached to the chest), stressed (immobilization for $2 \mathrm{~h}$ ); and trained/stressed (submitted to both procedures). Number of animals per group: nitric oxide synthase expression = 4; body weight and blood pressure $\Rightarrow$ control $=10$, trained $=15$. Values are means \pm SEM. 
aortal hyporeactivity to this vasoconstrictor agent. The effect of different levels of stress did not depend on what level of exercise training was present. There was not a statistically significant interaction between stress and exercise training. Moreover, none of these experimental procedures determined any change in the reactivity to noradrenaline of denuded aortas (Tables 1 and 2; Figure 3).

The endothelium removal produced a similar leftward shift of the curves for noradrenaline in aorta from all experimental groups. This procedure also determined an increase in the aorta maximum response to noradrenaline that reached similar values in all experimental groups. Consequently, the endothelium removal abolished the decrease in the maximum response to noradrenaline observed in intact aortas from rats exposed to acute stress and exercise training, isolated and in combination (Tables 1 and 2; Figure 3).

The presence of L-NAME also abolished the hyporeactivity to noradrenaline observed in intact aortas from trained and stressed rats, but not in intact aortas from trained rats exposed to stress.
This hyporeactivity was only partially recovered in the presence of the inhibitor (Table 1; Figure 3). Once restored, the maximal responses reached values similar to that observed in denuded aortas in the absence or presence of the inhibitor (Table 1; Figure 3). Besides, the presence of L-NAME determined a decrease in EC50 values for noradrenaline in intact aortas from all experimental groups. This decrease reached similar values to those observed in denuded aortas from all experimental groups, independently of the presence of the inhibitor (Table 2).

The presence of indomethacin determined a similar decrease in the maximum response to noradrenaline of intact aortas from sedentary and stressed rats. However, this procedure did not alter the maximum response to noradrenaline of intact aortas from trained rats submitted or not to stress relative to the same responses in the absence of this inhibitor. Consequently, this procedure did not abolish the hyporeactivity to noradrenaline observed in intact aortas from trained rats submitted or not to stress (Table 1; Figure 3). Besides, the presence of indomethacin determined

Table 1. Maximum response to noradrenaline, in absence or presence of indomethacin or L-NAME, obtained in two rings, one with and the other without endothelium, of the same thoracic aorta from sedentary and trained rats, submitted or not to stress.

\begin{tabular}{|c|c|c|c|c|c|c|c|c|}
\hline \multirow[t]{3}{*}{ Inhibitor } & \multicolumn{8}{|c|}{ Groups } \\
\hline & \multicolumn{2}{|c|}{ Sedentary } & \multicolumn{2}{|c|}{ Trained } & \multicolumn{2}{|c|}{ Stressed } & \multicolumn{2}{|c|}{ Trained/Stressed } \\
\hline & $+\mathbf{E}$ & $-\mathbf{E}$ & $+\mathbf{E}$ & $-\mathbf{E}$ & $+\mathbf{E}$ & $-\mathbf{E}$ & $+\mathbf{E}$ & $-\mathbf{E}$ \\
\hline Without & $\begin{array}{c}3.94 \pm 0.15 \\
\quad(n=9)\end{array}$ & $\begin{array}{c}5.25 \pm 0.30 \dagger \\
\quad(n=9)\end{array}$ & $\begin{array}{c}2.82 \pm 0.11 * \\
\quad(\mathrm{n}=10)\end{array}$ & $\begin{array}{c}4.92 \pm 0.47 \dagger \\
(n=10)\end{array}$ & $\begin{array}{c}2.80 \pm 0.10^{*} \\
(\mathrm{n}=9)\end{array}$ & $\begin{array}{c}5.28 \pm 0.31 \dagger \\
(\mathrm{n}=8)\end{array}$ & $\begin{array}{c}2.97 \pm 0.21 * \\
\quad(\mathrm{n}=10)\end{array}$ & $\begin{array}{c}5.12 \pm 0.59 \dagger \\
(\mathrm{n}=8)\end{array}$ \\
\hline Indomethacin & $\begin{array}{c}2.61 \pm 0.13 \# \\
(n=8)\end{array}$ & $\begin{array}{c}5.10 \pm 0.50 \dagger \\
(n=8)\end{array}$ & $\begin{array}{c}2.99 \pm 0.29 \\
(n=7)\end{array}$ & $\begin{array}{c}4.95 \pm 0.26 \dagger \\
(n=7)\end{array}$ & $\begin{array}{l}1.86 \pm 0.18^{* \#} \\
\quad(\mathrm{n}=8)\end{array}$ & $\begin{array}{c}4.99 \pm 0.29 \dagger \\
(n=8)\end{array}$ & $\begin{array}{c}2.80 \pm 0.18 \\
(n=8)\end{array}$ & $\begin{array}{c}4.91 \pm 0.19 \dagger \\
(\mathrm{n}=8)\end{array}$ \\
\hline L-NAME & $\begin{array}{c}5.23 \pm 0.26 \# \\
(n=7)\end{array}$ & $\begin{array}{c}4.95 \pm 0.29 \\
(n=7)\end{array}$ & $\begin{array}{c}5.28 \pm 0.30 \# \\
\quad(n=8)\end{array}$ & $\begin{array}{c}5.11 \pm 0.19 \\
(n=9)\end{array}$ & $\begin{array}{c}5.55 \pm 0.38 \# \\
(n=8)\end{array}$ & $\begin{array}{c}5.57 \pm 0.35 \\
(n=7)\end{array}$ & $\begin{array}{c}4.42 \pm 0.41 \# \\
(n=8)\end{array}$ & $\begin{array}{c}5.28 \pm 0.54 \dagger \\
(n=8)\end{array}$ \\
\hline
\end{tabular}

Maximum response in gram of tension; $(+\mathrm{E})$ : with endothelium; $(-\mathrm{E})$ : without endothelium; stress: immobilization for $2 \mathrm{~h}$; physical training: 60 -min swimming session $/ 5$ days/week during 8 weeks, with $5 \%$ body weight load attached to the chest. $* \mathrm{P}<0.05$ relate to sedentary group. \#P<0.05 presence of inhibitor $v s$ absence of inhibitor. $\uparrow \mathrm{P}<0.05$ rings without endothelium $v s$ rings with endothelium; values are means $\pm \mathrm{SEM}$; (n) $=$ number of animals; the data were compared by two-way ANOVA and complemented with the multiple comparisons Tukey's test.

Table 2. EC50 values for noradrenaline, in the absence or presence of indomethacin or L-NAME, obtained in two rings, one with and the other without endothelium, of the same thoracic aorta from sedentary and trained rats, submitted or not to stress.

\begin{tabular}{|c|c|c|c|c|c|c|c|c|c|c|c|c|c|c|c|c|}
\hline \multirow[t]{3}{*}{ Inhibitor } & \multicolumn{16}{|c|}{ Groups } \\
\hline & \multicolumn{4}{|c|}{ Sedentary } & \multicolumn{4}{|c|}{ Trained } & \multicolumn{4}{|c|}{ Stressed } & \multicolumn{4}{|c|}{ Trained/Stressed } \\
\hline & $+\mathbf{E}$ & $\mathbf{N}$ & $-\mathbf{E}$ & $\mathbf{N}$ & $+\mathbf{E}$ & $\mathbf{N}$ & $-\mathbf{E}$ & $\mathbf{N}$ & $+\mathbf{E}$ & $\mathbf{N}$ & $-\mathbf{E}$ & $\mathbf{N}$ & $+\mathbf{E}$ & $\mathbf{N}$ & $-\mathbf{E}$ & $\mathbf{N}$ \\
\hline Without & $\begin{array}{c}2.41 \\
(1.53-3.79)\end{array}$ & 9 & $\begin{array}{c}0.11 \dagger \\
(0.09-0.16)\end{array}$ & 9 & $\begin{array}{c}2.67 \\
(1.68-4.24)\end{array}$ & 10 & $\begin{array}{c}0.02 \dagger \\
(0.01-0.10)\end{array}$ & 10 & $\begin{array}{c}1.44 \\
(1.00-2.09)\end{array}$ & 9 & $\begin{array}{c}0.03 \dagger \\
(0.01-0.18)\end{array}$ & 8 & $\begin{array}{c}5.34 \\
(3.27-6.64)\end{array}$ & 10 & $\begin{array}{c}0.11 \dagger \\
(0.01-0.21)\end{array}$ & 8 \\
\hline Indomethacin & $\begin{array}{c}0.29 * \\
(0.13-0.61)\end{array}$ & 8 & $\begin{array}{c}0.06^{\dagger} \\
(0.01-0.30)\end{array}$ & 8 & $\begin{array}{c}0.26^{*} \\
(0.07-0.97)\end{array}$ & 7 & $\begin{array}{c}0.05^{\dagger} \\
(0.02-0.14)\end{array}$ & 7 & $\begin{array}{c}0.41 * \\
(0.10-1.66)\end{array}$ & 8 & $\begin{array}{c}0.07 \dagger \\
(0.02-0.22)\end{array}$ & 8 & $\begin{array}{c}2.51 \\
(1.17-5.38)\end{array}$ & 8 & $\begin{array}{c}0.08 \dagger \\
(0.04-0.17)\end{array}$ & 8 \\
\hline L-NAME & $\begin{array}{c}0.09 * \\
(0.01-0.12)\end{array}$ & 7 & $\begin{array}{c}0.10 \dagger \\
(0.05-0.30)\end{array}$ & 7 & $\begin{array}{c}0.11 * \\
(0.04-0.31)\end{array}$ & 8 & $\begin{array}{c}0.08 \dagger \\
(0.04-0.16)\end{array}$ & 9 & $\begin{array}{c}0.10^{*} \\
(0.03-0.43)\end{array}$ & 7 & $\begin{array}{c}0.04 \dagger \\
(0.01-0.10)\end{array}$ & 8 & $\begin{array}{c}0.10^{*} \\
(0.01-1.11)\end{array}$ & 8 & $\begin{array}{c}0.12 \dagger \\
(0.02-0.10)\end{array}$ & 8 \\
\hline
\end{tabular}

Values are EC50 $\left(\times 10^{-7} \mathrm{M}\right)$ : concentration of noradrenaline producing a response that was $50 \%$ of the maximum effect; $(+\mathrm{E}$ : with endothelium; (-E): without endothelium; stress: immobilization for 2 h; physical training: 60 -min swimming session/5 days/week during 8 weeks, with $5 \%$ body weight load attached to the chest; values are means with $95 \%$ confidence interval. $* \mathrm{P}<0.05$ presence of inhibitor $v s$ absence of inhibitor, in rings with endothelium. $† \mathrm{P}<0.05$ relate to rings with endothelium; $(\mathrm{N})=$ number of animals; the data were compared by two-way ANOVA and complemented with the multiple comparisons Tukey's test. 
With endothelium
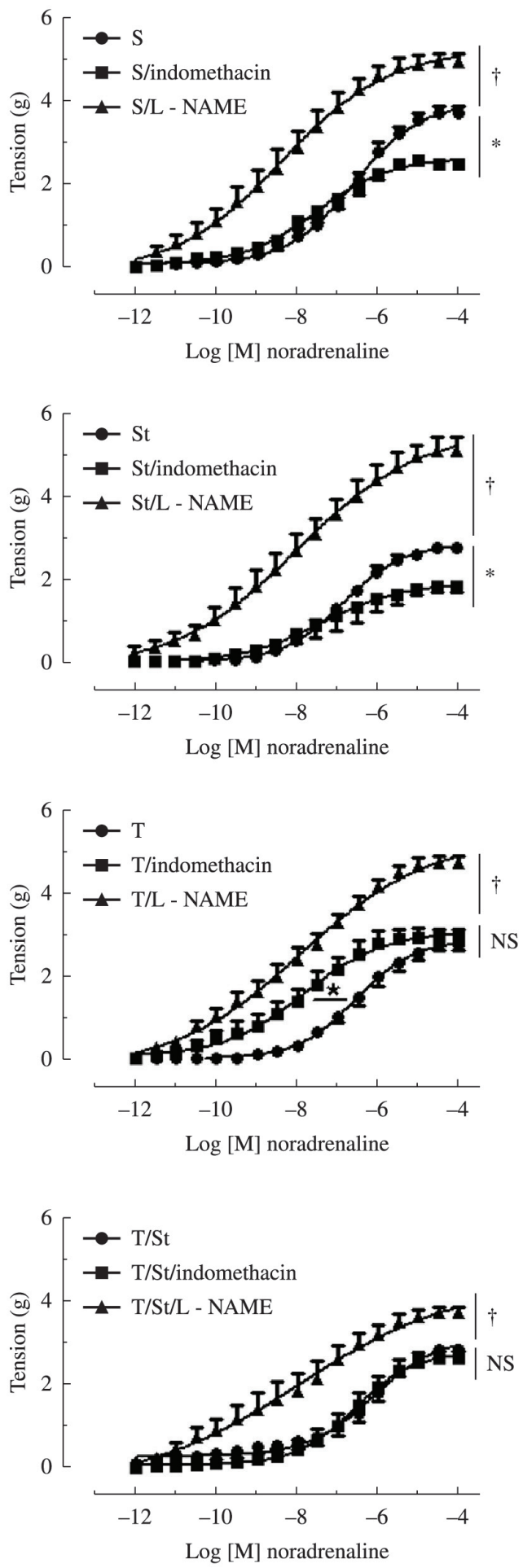

Without endothelium
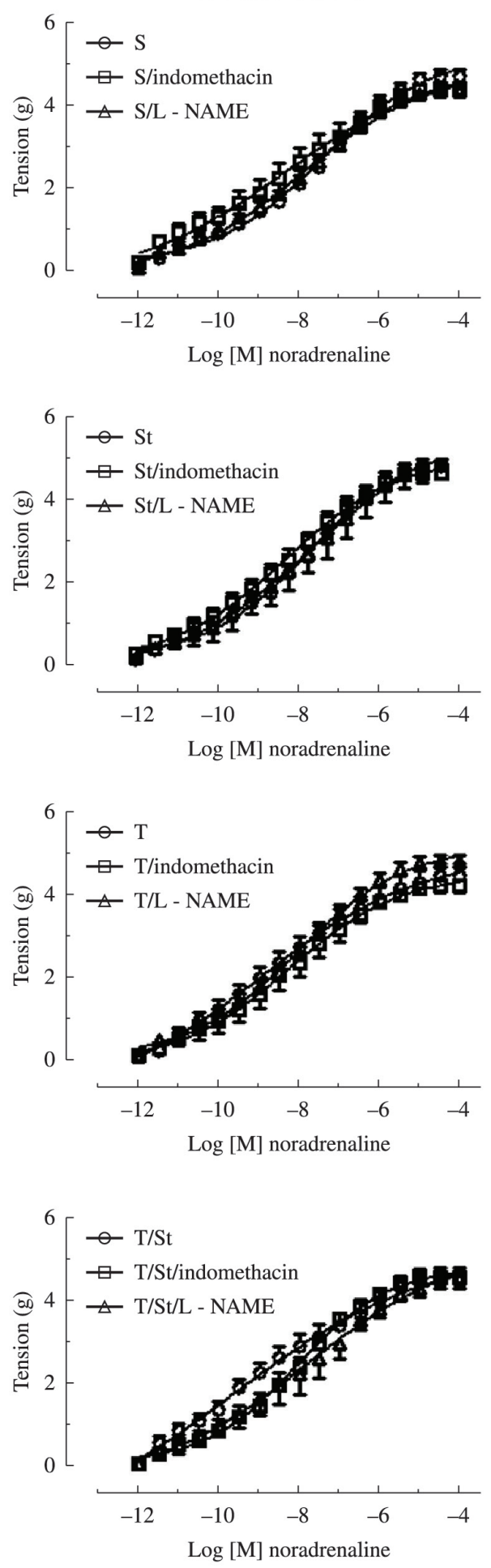

Figure 3. Concentration-effect curves for noradrenaline, in the presence or absence of indomethacin $\left(10^{-5} \mathrm{M}\right)$ or L-NAME $\left(3 \times 10^{-4} \mathrm{M}\right)$, obtained in two rings, with and without endothelium, of thoracic aortas from 16-week old rats. Groups: (S) sedentary; (T) trained (60-min swimming sessions, 5 days/week during 8 weeks, with a $5 \%$ body weight load attached to the chest); (St) submitted to acute stress (immobilization for $2 \mathrm{~h}$ ); and (T/St) submitted to both procedures. ${ }^{*} \mathrm{P}<0.05$ presence of indomethacin $v s$ absence of inhibitor. ${ }^{\dagger} \mathrm{P}<0.05$ presence of L-NAME $v s$ absence of inhibitor. Values are means \pm SEM of 7-10 animals per group. The data were compared by two-way ANOVA and complemented with the multiple comparison Tukey's test. 
a similar decrease in EC50 values for noradrenaline in intact aortas from all experimental groups, except in intact aortas from trained rats submitted to stress (Table 2).

The presence of the inhibitors did not alter the reactivity to noradrenaline of denuded aorta from all experimental groups (Tables 1 and 2; Figure 3).

\section{- Discussion}

In the present study, exercise training had no effect on body weight gain, corroborating previous reports from the literature showing that unless the overall volume of aerobic exercise training is very high, clinically significant weight loss is unlikely to occur ${ }^{17}$.

Various investigators have used the fresh weight of the adrenal gland, an organ that responds to stress, as indicative of stressogenic conditions. The weight of the adrenal gland may be reduced or may remain unchanged after exposure to acute stress, but is often increased by chronic stress ${ }^{18,19}$. In the present study, the mean fresh weight of the adrenal glands was significantly reduced, showing that acute stress was effective in the experimental protocol proposed. Contrarily, exercise did not alter the adrenal weight, suggesting that the employed protocol did not represent a stressogenic condition.

In addition, left ventricular hypertrophy was observed in rats submitted to the exercise training program. It is well known that physical exercise is a stimulus for the development of left ventricular hypertrophy, which occurs to maintain not only the relative constancy of ventricular wall stress, but also the adequacy of the stroke volume, so that the resulting structural changes depend on the nature, duration, and intensity of exercise ${ }^{20}$. Hypertrophy may represent a physiological and beneficial cardiac adaptation, usually associated with enhanced heart function. Thus, the left ventricular hypertrophy shows the effectiveness of the employed exercise training program.

The success of physical training in reducing blood pressure is dependent on the type and intensity of the exercise protocol ${ }^{21}$. However, this effect is only observed in hypertensive individuals ${ }^{22}$. Thus, the effects of physical training on blood pressure of normotensive humans and animals are described as minimal ${ }^{16,23,24}$. Corroborating these findings, the exercise training program did not determine significant differences in blood pressure of trained rats compared to sedentary ones.
The exercise training also induced a vascular adaptive response characterized by hyporeactivity to noradrenaline, which was shown to be dependent on the integrity of the endothelial cells since it was abolished by endothelium removal. A similar hyperactivity of endothelial cells was previously reported in conditions that, like exercise, involve prolonged activation of adrenoceptors, such as stress and diet-induced obesity ${ }^{2,25,26}$. Indeed, the acute stress exposure determined a decrease in the maximum response to noradrenaline in aortas of sedentary rats, which was shown to be dependent on endothelium integrity since it was abolished by endothelium removal.

In order to assess the mechanisms involved in the endothelial cell hyperactivity induced by both exercise training and acute stress exposure, L-NAME (inhibitor of NOS) and indomethacin (inhibitor of prostaglandin production) were used. L-NAME, but not indomethacin, abolished the exercise-induced decrease in the aorta reactivity to noradrenaline. Although indomethacin did not abolish the hyporeactivity to noradrenaline, its presence elicited supersensitivity to noradrenaline, characterized by a decrease in the EC50 value in aortic rings isolated from rats submitted to exercise training. The data strongly suggest a different grade of contribution of the endothelium-derived relaxing factors, nitric oxide and prostanoids, for the vascular adaptive response induced by exercise. Moreover, this differential contribution was shown to be dependent on noradrenaline levels. At high levels of circulating catecholamines, nitric oxide would be the main factor controlling vascular tone, whereas vasodilating prostanoids have greater involvement in the control of vascular tone at moderate levels of catecholamines. Different involvement of prostanoids and nitric oxide in the control of coronary vascular tone to different levels of physical activity was previously reported in pigs ${ }^{27}$. According Osanai et al. ${ }^{28}$, nitric oxide and prostanoids are generated by shear stress during exercise training, which contribute to the vascular relaxation. Thus, the present study allows us to suggest a major role of nitric oxide compared to vasodilator prostanoids in the control of aorta tone in subjects who practice physical exercise daily.

The immunohistochemical studies also confirmed the exercise-induced increase in nitric oxide production since this procedure has determined an increase in the aortic NOS 1 expression in trained rats. Increase in NOS expression in aorta of rats submitted to physical exercise was previously reported by Delp and Laughlin ${ }^{29}$. 
The stress-induced vascular adaptive response in sedentary rats was also abolished in the presence of L-NAME, but not in the presence of indomethacin, corroborating previous studies from our laboratory ${ }^{2}$. Besides, stress-exposure determined an increase in the aortic $\mathrm{NOS}_{1}$ expression, which was assessed by immunohistochemical studies. These data strongly suggest that stress-induced hyporeactivity to noradrenaline in aortas of sedentary rats involves an increase in the production, release and/or bioavailability of nitric oxide. The results also allow us to discard the involvement of vasodilating prostaglandins in the stress-induced vascular adaptive response. Moreover, the increased endothelial bioavailability of nitric oxide might be considered a mechanism to counteract the deleterious cardiovascular effects of stress exposure.

Since physical exercise may modify biologic stress responses ${ }^{7,8}$, a study investigated the impact of exercise training on vascular alterations induced by acute immobilization stress, a useful model of emotional stress ${ }^{30}$. Although the combination of exercise training and acute stress has also determined an endothelium-dependent hyporeactivity to noradrenaline, this procedure did not result in a synergistic effect on the vascular reactivity. Moreover, the presence of indomethacin did not abolish the aortal hyporeactivity to noradrenaline induced by the combination of exercise and stress suggesting that vasodilating prostaglandins are not involved in the vascular adaptive response induced by exercise training in combination with stress-exposure. Unlike what happened with exercise and stress alone, the presence of L-NAME partially abolished the hyporeactivity to noradrenaline induced by the combination of both procedures. Moreover, the combination of exercise and stress also determined an increase in the aortic $\mathrm{NOS}_{1}$ expression but to a lesser degree than after exercise training and stress-exposure alone. Altogether, the results suggest that the vascular adaptive response induced by exercise training in combination with acute stress-exposure involves a hyperactivity of the endothelial cells, characterized by an increase in the production and/or bioavailability of two important endothelium-derived relaxing factors. One factor, sensitive to L-NAME, seems to be nitric oxide. However, the identity of the other factor, resistant to L-NAME and indomethacin, remains to be determined.

In summary, exercise training and stress-exposure determined vascular adaptive responses, characterized by hyperactivity of endothelial cells; however, the combination of both procedures did not result in synergistic effect. Moreover, the vascular adaptive response induced by exercise training was shown to be dependent on two important endothelium-derived relaxing factors, nitric oxide, and vasodilating prostaglandins. Differently, the vascular adaptive response induced by acute emotional stress was shown to be only dependent on nitric oxide pathway. Finally, in addition to the involvement of the endothelial nitric oxide pathway, the vascular response of trained/stressed rats involved an additional mechanism still to be elucidated. These findings advance on the understanding of the vascular processes after exercise training and stress-exposure alone and in combination. They could also aid in new strategies related to exercise training improvement of stress-related cardiovascular events mainly those associated with pathologies that impair nitric oxide pathway.

\section{Acknowledgements}

To Fundação de Amparo à Pesquisa do Estado de São Paulo (FAPESP), Brazil, for their financial support (process no. 06/57200-8).

\section{References}

1. Bruder-Nascimento T, Cordellini S. Vascular adaptive responses to physical exercise and to stress are affected differently by nandrolone administration. Braz J Med Biol Res. 2011;44(4):337-44. http://dx.doi.org/10.1590/S0100879X2011007500043. PMid:21445526.

2. Cordellini S, Vassilieff VS. Decreased endothelium-dependent vasoconstriction to noradrenaline in acute-stressed rats is potentiated by previous chronic stress: nitric oxide involvement. Gen Pharmacol. 1998;30(1):79-83. http:// dx.doi.org/10.1016/S0306-3623(97)00074-8. PMid:9457485.

3. Collier SR, Kanaley JA, Carhart R Jr, Frechette V, Tobin MM, Hall AK, et al. Effect of 4 weeks of aerobic or resistance exercise training on arterial stiffness, blood flow and blood pressure in pre- and stage-1 hypertensives. J Hum Hypertens. 2008;22(10):678-86. http://dx.doi.org/10.1038/ jhh.2008.36. PMid: 18432253 .

4. Moraes R, Gioseffi G, Nóbrega AC, Tibiriçá E. Effects of exercise training on the vascular reactivity of the whole kidney circulation in rabbits. J Appl Physiol (1985). 2004;97(2):6838. http://dx.doi.org/10.1152/japplphysiol.00923.2003. PMid:15090484

5. Lenasi H, Strucl M. Effect of regular physical training on cutaneous microvascular reactivity. Med Sci Sports Exerc. 2004;36(4):606-12. http://dx.doi.org/10.1249/01. MSS.0000121948.86377.51. PMid:15064588.

6. Deer RR, Heaps CL. Exercise training enhances multiple mechanisms of relaxation in coronary arteries from ischemic hearts. Am J Physiol Heart Circ Physiol. 2013;305(9):H1321-31. http://dx.doi.org/10.1152/ajpheart.00531.2013. PMid:23997097. 
7. Lavie CJ, Milani RV, O'Keefe JH, Lavie TJ. Impact of exercise training on psychological risk factors. Prog Cardiovasc Dis. 2011;53(6):464-70. http://dx.doi.org/10.1016/j. pcad.2011.03.007. PMid:21545933.

8. Hamer M. Psychosocial stress and cardiovascular disease risk: the role of physical activity. Psychosom Med. 2012;74(9):896903. http://dx.doi.org/10.1097/PSY.0b013e31827457f4. PMid:23107839.

9. Huang CJ, Webb HE, Zourdos MC, Acevedo EO. Cardiovascular reactivity, stress, and physical activity. Front Physiol. 2013;4:314. http://dx.doi.org/10.3389/fphys.2013.00314. PMid:24223557.

10. Stults-Kolehmainen MA. The interplay between stress and physical activity in the prevention and treatment of cardiovascular disease. Front Physiol. 2013;4:346. http:// dx.doi.org/10.3389/fphys.2013.00346. PMid:24348424.

11. Demarzo MM, Montero-Marin J, Stein PK, Cebolla A, Provinciale JG, García-Campayo J. Mindfulness may both moderate and mediate the effect of physical fitness on cardiovascular responses to stress: a speculative hypothesis. Front Physiol. 2014;5:105. http://dx.doi.org/10.3389/ fphys.2014.00105. PMid:24723891.

12. Moreira SR, Lima RM, Silva KE, Simões HG. Combined exercise circuit session acutely attenuates stress-induced blood pressure reactivity in healthy adults. Braz J Phys Ther. 2014;18(1):38-46. http://dx.doi.org/10.1590/S141335552012005000135 . PMid:24675911.

13. Holtermann A, Mortensen OS, Burr H, Søgaard K, Gyntelberg F, Suadicani P. Physical demands at work, physical fitness, and 30-year ischaemic heart disease and all-cause mortality in the Copenhagen Male Study. Scand J Work Environ Health. 2010;36(5):357-65. http://dx.doi.org/10.5271/sjweh.2913. PMid:20352174.

14. Nunes S, Soares E, Fernandes J, Viana S, Carvalho E, Pereira FC, et al. Early cardiac changes in a rat model of prediabetes: brain natriuretic peptide overexpression seems to be the best marker. Cardiovasc Diabetol. 2013;12(1):44. http:// dx.doi.org/10.1186/1475-2840-12-44. PMid:23497124.

15. Selye H, Collip JB. Fundamental factors in the interpretation of stimuli influencing endocrine glands. Endocrinology. 1936;20(5):667-72. http://dx.doi.org/10.1210/endo-20-5-667.

16. Medeiros A, Oliveira EM, Gianolla R, Casarini DE, Negrão $\mathrm{CE}$, Brum PC. Swimming training increases cardiac vagal activity and induces cardiac hypertrophy in rats. Braz J Med Biol Res. 2004;37(12):1909-17. http://dx.doi.org/10.1590/ S0100-879X2004001200018. PMid:15558199.

17. Swift DL, Johannsen NM, Lavie CJ, Earnest CP, Church TS. The role of exercise and physical activity in weight loss and maintenance. Prog Cardiovasc Dis. 2014;56(4):441-7. http://dx.doi.org/10.1016/j.pcad.2013.09.012. PMid:24438736.

18. Van Dijken HH, de Goeij DC, Sutanto W, Mos J, de Kloet ER, Tilders FJ. Short inescapable stress produces long-lasting changes in the brain-pituitary-adrenal axis of adult male rats. Neuroendocrinology. 1993;58(1):57-64. http://dx.doi. org/10.1159/000126512. PMid:8264856.

19. Ricart-Jané D, Rodríguez-Sureda V, Benavides A, PeinadoOnsurbe J, López-Tejero MD, Llobera M. Immobilization stress alters intermediate metabolism and circulating lipoproteins in the rat. Metabolism. 2002;51(7):925-31. http://dx.doi.org/10.1053/meta.2002.33353. PMid:12077743.
20. Ghorayeb N, Batlouni M, Pinto IMF, Dioguardi GS. Hipertrofia ventricular esquerda do atleta: resposta adaptativa fisiológica do coração. Arq Bras Cardiol. 2005;85(3):191-7. http://dx.doi. org/10.1590/S0066-782X2005001600008. PMid:16200266.

21. Véras-Silva AS, Mattos KC, Gava NS, Brum PC, Negrão CE, Krieger EM. Low-intensity exercise training decreases cardiac output and hypertension in spontaneously hypertensive rats. Am J Physiol. 1997;273(6 Pt 2):H2627-31. PMid:9435596.

22. Silva GJ, Brum PC, Negrão CE, Krieger EM. Acute and chronic effects of exercise on baroreflexes in spontaneously hypertensive rats. Hypertension. 1997;30(3 Pt 2):714-9. http://dx.doi.org/10.1161/01.HYP.30.3.714. PMid:9323011.

23. Cornelissen VA, Smart NA. Exercise training for blood pressure: a systematic review and meta-analysis. J Am Heart Assoc. 2013;2(1):e004473. http://dx.doi.org/10.1161/ JAHA.112.004473. PMid:23525435.

24. Desai KH, Sato R, Schauble E, Barsh GS, Kobilka BK, Bernstein D. Cardiovascular indexes in the mouse at rest and with exercise: new tools to study models of cardiac disease. Am J Physiol. 1997;272(2 Pt 2):H1053-61. PMid:9124413.

25. Nascimento TB, Baptista RF, Pereira PC, Campos DH, Leopoldo AS, Leopoldo AP, et al. Alterações vasculares em ratos obesos por dieta rica em gordura: papel da Via L-arginina/NO Endotelial. Arq Bras Cardiol. 2011;97(1):405. http://dx.doi.org/10.1590/S0066-782X2011005000063. PMid:21603776.

26. Jansakul C. Effect of swimming on vascular reactivity to phenylephrine and $\mathrm{KC1}$ in male rats. Br J Pharmacol. 1995;115(4):587-94. http://dx.doi.org/10.1111/j.1476-5381.1995. tb14972.x. PMid:7582476.

27. Merkus D, Sorop O, Houweling B, Boomsma F, van den Meiracker AH, Duncker DJ. NO and prostanoids blunt endothelin-mediated coronary vasoconstrictor influence in exercising swine. Am J Physiol Heart Circ Physiol. 2006;291(5):H2075-81. http://dx.doi.org/10.1152/ ajpheart.01109.2005. PMid:16751289.

28. Osanai T, Fujita N, Fujiwara N, Nakano T, Takahashi K, Guan W, et al. Cross talk of shear-induced production of prostacyclin and nitric oxide in endothelial cells. Am J Physiol Heart Circ Physiol. 2000;278(1):H233-8. PMid:10644603.

29. Delp MD, Laughlin MH. Time course of enhanced endothelium-mediated dilation in aorta of trained rats. Med Sci Sports Exerc. 1997;29(11):1454-61. http://dx.doi. org/10.1097/00005768-199711000-00011. PMid:9372482.

30. Ebner K, Rupniak NM, Saria A, Singewald N. Substance P in the medial amygdala: emotional stress-sensitive release and modulation of anxiety-related behavior in rats. Proc Natl Acad Sci USA. 2004;101(12):4280-5. http://dx.doi. org/10.1073/pnas.0400794101. PMid:15024126.

\section{Correspondence}

Sandra Cordellini

Universidade Estadual Paulista

Departamento de Farmacologia

Instituto de Biociências

Distrito Rubião Júnior, $\mathrm{s} / \mathrm{n}$

CEP 18618-000, Botucatu, SP, Brasil

e-mail: cordelli@ibb.unesp.br 